\title{
A Large-scale Pilot Breast Cancer Screening Program: Findings and Recommendations for National Screening Programs
}

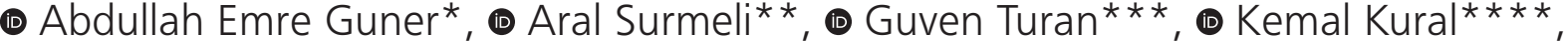 \\ (-) Engin Ersin Simsek ${ }^{* * * *}$, (1) Isil Maral ${ }^{* * *}$ \\ *Istanbul Health Directorate, Public Health Services, Istanbul, Turkey \\ **HERA INC., Boston, United States of America \\ ***Istanbul Medeniyet University Faculty of Medicine, Department of Public Health, Istanbul, Turkey \\ $* * * *$ Istanbul Health Directorate, Monitoring, Evaluation and Statistics, Istanbul, Turkey \\ $* * * *$ University of Health Sciences Turkey, Istanbul Kartal Dr. Lutfi Kirdar Health Application and Research Center, Istanbul, Turkey
}

Abstract

Aim: Breast cancer is the most prevalent cancer diagnosed in women. Screening programs to diagnose breast anomalies increase the likelihood of early diagnosis and survival. This study describes the most extensive breast cancer screening program in Istanbul/Turkey between 2018 and 2019 and offers recommendations for nationwide programs.

Methods: We collected data from the Istanbul Health Directorate's cancer surveillance database from May 2018 to December 2019. We analyzed data on patients referred for further investigation due to suspicion of possible tumors in their screening radiography. The database included socio-demographic information and further examination details (tests, outcomes, and planned treatment).

Results: The mean age of the 3,577 women who were invited for further examination was 52.3 [standard deviation (SD): 7.5]. The age group with the highest percentage of further investigation invitations was between 50 and 54 . The mean time between the results of screening mammography was 16.2 days (SD: 15.3). 5.1\% of the women referred were diagnosed with some sort of cancer. Women who went to the place of scheduled appointments, instead of getting an appointment in another place of their choosing, were diagnosed and treated earlier.

Conclusion: For a breast screening program to reach the entirety of the target population, a comprehensive approach to every step of the process (screening, diagnosis, treatment) needs to be considered together.

Keywords: Breast cancer screening, imaging, mammography, screening

\section{Introduction}

Breast cancer is the most prevalent cancer in women, with 2.08 million yearly cases and 626,000 fatal cases (1). Breast cancer data from Turkey is also similar. One in every four cancer diagnoses in women is breast cancer (2). Survival rates of localized spread stages and metastatic stages are $85.7 \%$ and $28.1 \%$, respectively (3). While the disease is a type of progressive cancer, early diagnosis and treatment provide to decreased mortality and morbidity (4).
Recommended methods for early detection of breast cancer include breast self-examination, clinical examination, and breast mammography, the latter being the gold standard for complete cancer screening (5). Screening for breast cancer decreases breast cancer mortality if implemented for the appropriate age group and recommended frequencies (6-8). While consensus on the frequency of mammography has not been established, the American Cancer Society recommends yearly screening between the ages of 45 to 55 and 
every two years after the age of 55 (9). However, the Turkish Ministry oh Health starts screening procedures at age 40 .

In light of the evidence, the Turkish Ministry of Health planned to undertake a nationwide screening program through these 15 centers in Istanbul as a pilot. During the implementation of this program, there were 2,529.072 women in the target age group (10). This study presents the initial results of the pilot program involving forty-seven thousand women living in Turkey.

This screening protocol is implemented by Cancer Diagnosis, Screening, and Education Center [Erken Teşhis, Tarama ve Eğitim Merkezleri (KETEM)] and their mobile services, which are overseen by the Ministry of Health. These centers were open to the public, and anyone in the target group could come in for screening without the need for an appointment, free of charge. If the findings necessitate further investigation, the women would be contacted by family physicians, who are assigned to each individual in Turkey. Physicians contact the person via calls, emails, or short message services and are invited for voluntary screening.

The aim of this study is to evaluate the screening process, discuss the feasibility of large-scale screening programs, and produce insights for implementation for nationwide uptake of such a program.

\section{Methods}

An Internal Review Board approval was received from Istanbul Medeniyet University Goztepe Training and Research Hospital Clinical Research Ethics Committee (date: 27.01.2021 and approval number: 2021/0055). No informed consent was sought as the study only used data from the existing databases.

This is a cross-sectional study that enrolled data already collected by Istanbul Municipal Health Directorate Public Health Services in National Breast Cancer Screening Program. The program started collecting data in May 2018. This study includes all the data available from May 2019 to December 2019. For the purposes of this study, all available data from the database was used. Variables included socio-demographic information, details of appointments, diagnostic choices, diagnosis, and treatment.

\section{Screening Procedure}

Mammography of invited participants is done through either the KETEM or their two mobile units. Diagnostic results of mammography are evaluated and decided by Hacettepe University Medical School Radiography Department. Results are directed to Municipal Health Directorates then to the district health directorate or primary care centers. Screened women with positive (or suspected) results are called to inform the participant and schedule further tests by either their primary care physicians or the Cancer Screening Department of the district health directorate. Simultaneously, data from the women who accepted further tests is entered into a shared database. Further data collection and input are done by the hospital personnel where the participant chooses to go. If the participant rejects further testing, the data collected stays in the district health directorate level for calling again at a later date. This algorithm is summarized in Figure 1.

Data collected includes contact information, date of birth, dates, and details of each test, district name, diagnosis, and treatment details. For the purposes of this study, all variables except planned/ongoing treatment details are used.

\section{Statistical Analysis}

We analyzed the data with SPSS version 22.0. Descriptive statistics are presented as percentages, frequencies, means, medians, and standard deviations (interquartile range). We compared medians with the Student's t-test and paired t-test after assumptions were affirmed. The statistical difference was set as $p<0.05$. Statistical tests done are presented as a separate table (Table 1).

\section{Results}

The screening program included 47,698 women. 3,577 of the screened participants $(7.5 \%)$ were referred for further investigation. Health Directorate personnel were able to reach $97.7 \%$ (3,490 women) of them to refer them for further testing. Efforts to reach $2.4 \%$ were unsuccessful. In total, 3,086 women (86.3\%) accepted the invitation to set up a referral appointment. Enrollment and follow-up of participants are summarized in Figure 2. Information on the people who did not accept an appointment but then made an appointment by themselves was added later.

Of the women referred for further investigation $(3,577)$, the mean age was 52.3 [Standard deviation (SD):7.5]. Final diagnosis and further investigation results were available

Table 1. Statistical test variables, measured outcome and p-value

\begin{tabular}{|l|l|l|l|}
\hline Group 1 & Group 2 & Measured outcome & Test \\
\hline $\begin{array}{l}\text { Persons who went to the set } \\
\text { appointment }\end{array}$ & $\begin{array}{l}\text { Persons who did not go to the } \\
\text { set appointment }\end{array}$ & Completeness of outcome data (\%) & Chi-squared \\
\hline $\begin{array}{l}\text { Persons who went to the set } \\
\text { appointment }\end{array}$ & $\begin{array}{l}\text { Persons who did not go to the } \\
\text { set appointment }\end{array}$ & $\begin{array}{l}\text { Days between the result of initial } \\
\text { mammography test and further } \\
\text { testing appointment }\end{array}$ & Paired t-test \\
\hline
\end{tabular}




\begin{tabular}{|c|c|c|}
\hline & & n (\%) \\
\hline \multirow{7}{*}{ Age groups } & $40-44$ & $488(13.6 \%)$ \\
\hline & $45-49$ & $1,084(30.3 \%)$ \\
\hline & $50-54$ & $748(20.9 \%)$ \\
\hline & 55-59 & $591(16.5 \%)$ \\
\hline & $60-64$ & 368 (10.3\%) \\
\hline & $65+$ & $298(8.3 \%)$ \\
\hline & Total & 3,577 (100\%) \\
\hline \multirow{5}{*}{$\begin{array}{l}\text { Appointment } \\
\text { place of further } \\
\text { investigation }\end{array}$} & Unreachable & $85(2.4 \%)$ \\
\hline & In the appointment center & $2,832(81.1 \%)$ \\
\hline & Another center & $519(14.9 \%)$ \\
\hline & Appointment not made & $54(1.6 \%)$ \\
\hline & Total & $3,490(100 \%)$ \\
\hline \multirow{6}{*}{$\begin{array}{l}\text { Method of } \\
\text { investigation }\end{array}$} & $\begin{array}{l}\text { One or more radiological } \\
\text { test }\end{array}$ & $2,758(82.3 \%)$ \\
\hline & Biopsy & $353(10.6 \%)$ \\
\hline & No further testing & $15(0.4 \%)$ \\
\hline & Further testing rejected & $85(2.5 \%)$ \\
\hline & $\begin{array}{l}\text { Unknown or ongoing } \\
\text { process }\end{array}$ & $140(4.2 \%)$ \\
\hline & Total & $3,351(100 \%)$ \\
\hline \multirow{4}{*}{ Diagnosis } & Normal & $2,295(68.5 \%)$ \\
\hline & Cancer & $191(5.7 \%)$ \\
\hline & $\begin{array}{l}\text { Unknown or ongoing } \\
\text { process }\end{array}$ & $865(25.8 \%)$ \\
\hline & Total & 3,351 (100\%) \\
\hline
\end{tabular}

for 2,486 people. Age groups, further investigation, and diagnostic procedure details are presented in Table 2 .

Out of 3,490 women who had their appointment set, $81.1 \%(2,832$ women $)$ went to the scheduled appointment, while the rest went to another health center of their choosing (14.9\%) or did not receive the appointment (Table 2). The mean number of days between the results of screening mammography and scheduling the further testing appointment is 16.2 (SD: 15.3) and the mean day between the results and the actual day of the appointment is 27.1 (SD: 37.2). There was a statistical difference between the number of days from the results of the initial mammography to the day of the further testing appointment between people who went to the place of appointment (mean: 26.6, SD: 37.1 days) and people who went to another place of their choice (mean: 39.9, SD: 43.4 days), (paired t-test, $p=0.0052$ ).

Among further testing methods, $82.3 \%$ of the patients received one or more radiological tests, and 10.3\% received a biopsy (Table 2). There was a marked difference in the completeness of diagnostic methods between the data of patients who went to the place of appointment (4.3\% incomplete data) and patients who went to another place (30.4\% incomplete data) (chi-squared test $p<0.001$ ). Diagnostic tests done are summarized in Graph 1.

In total, there were 191 diagnoses of any kind of breast cancer in the population for which data was available $(2,486$ women). The mean age of women who received a cancer diagnosis of cancer was 55.2 (SD: 8.0), older than

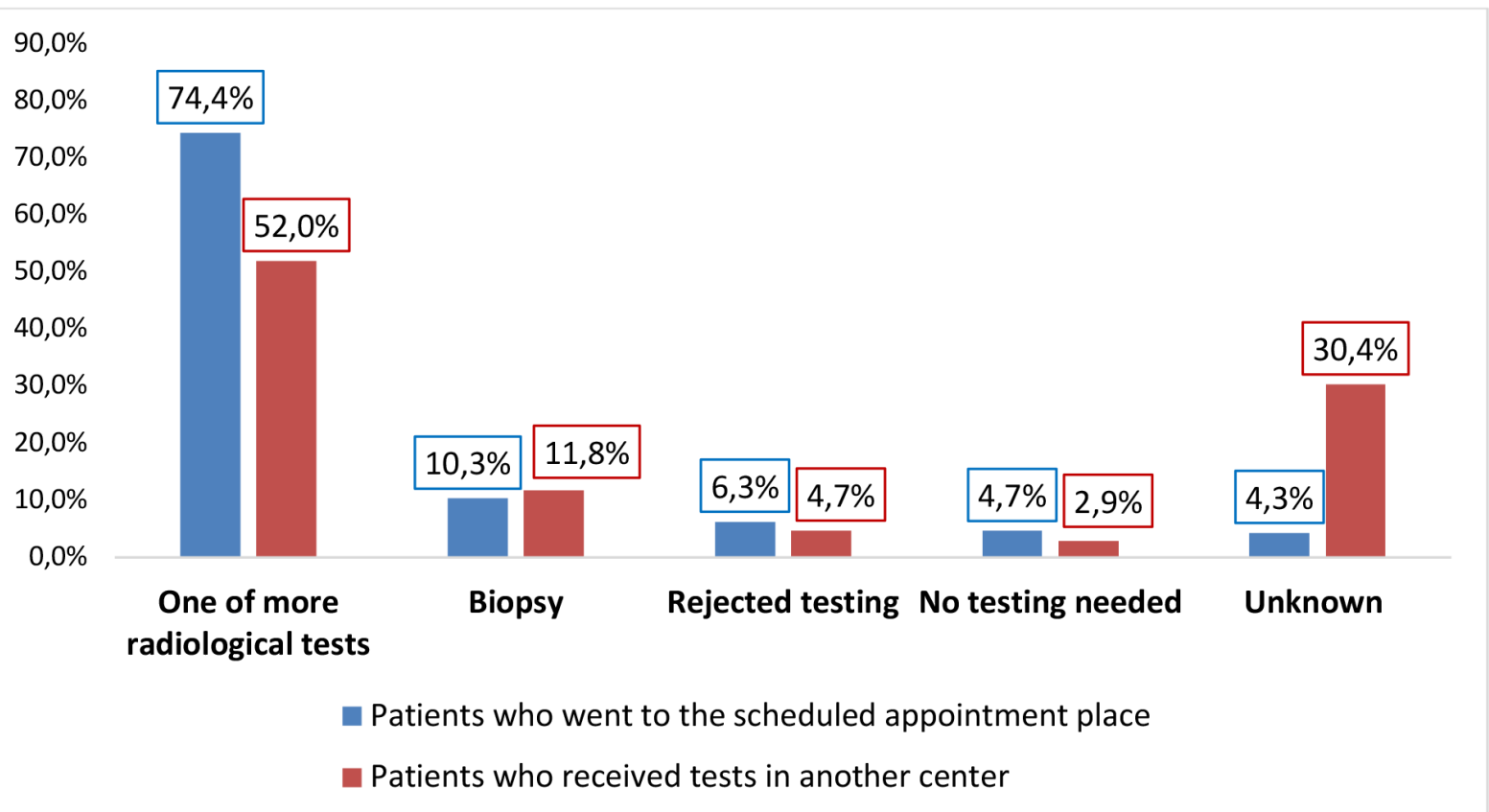

Graph 1. Diagnostic tests done by place of appointment 
the whole screened group. While only $56 \%$ of the women screened were over the age of 50 , the ratio was $69 \%$ in the group that received a breast cancer diagnosis.

\section{Discussion}

This study aims to describe a large-scale breast cancer screening program, the first of its kind in Istanbul, Turkey. We hope the findings on screening and follow-up will be beneficial in implementing similar interventions through primary care services. In the program's scope, 47,698 women were screened, 3,577 (\%) were referred for further testing, and 191 (5\% among those referred and $0.4 \%$ among the screened) received a diagnosis and treatment.

Four out of five women whose mammography was done are over 45 years of age. While guidelines in the U.S. and Europe typically recommend screening at least 45-50 years of age, the Turkish screening program starts at forty $(11,13)$. There is existing local literature that finds similar breast cancer rates between the ages of

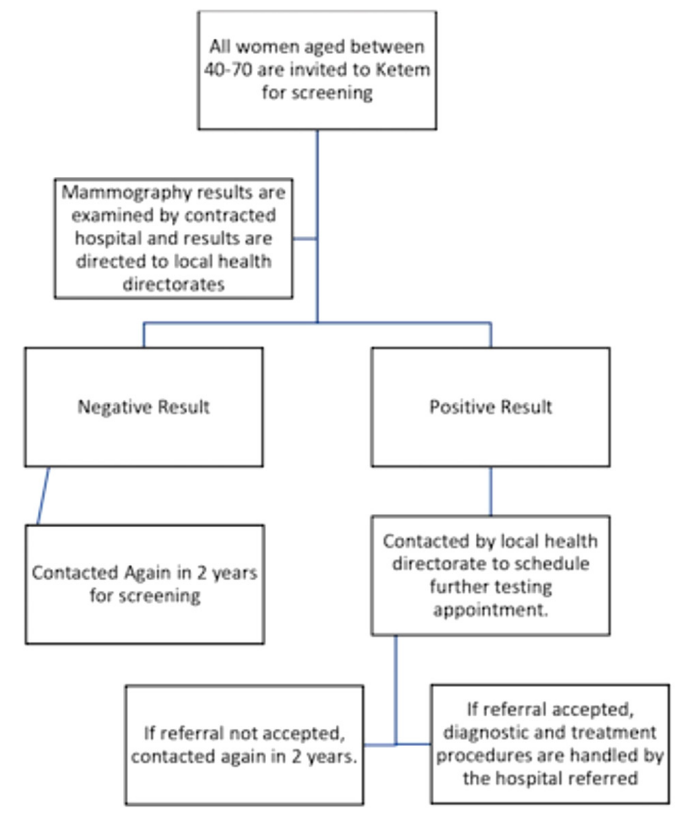

Figure 1. Breast cancer screening algorithm

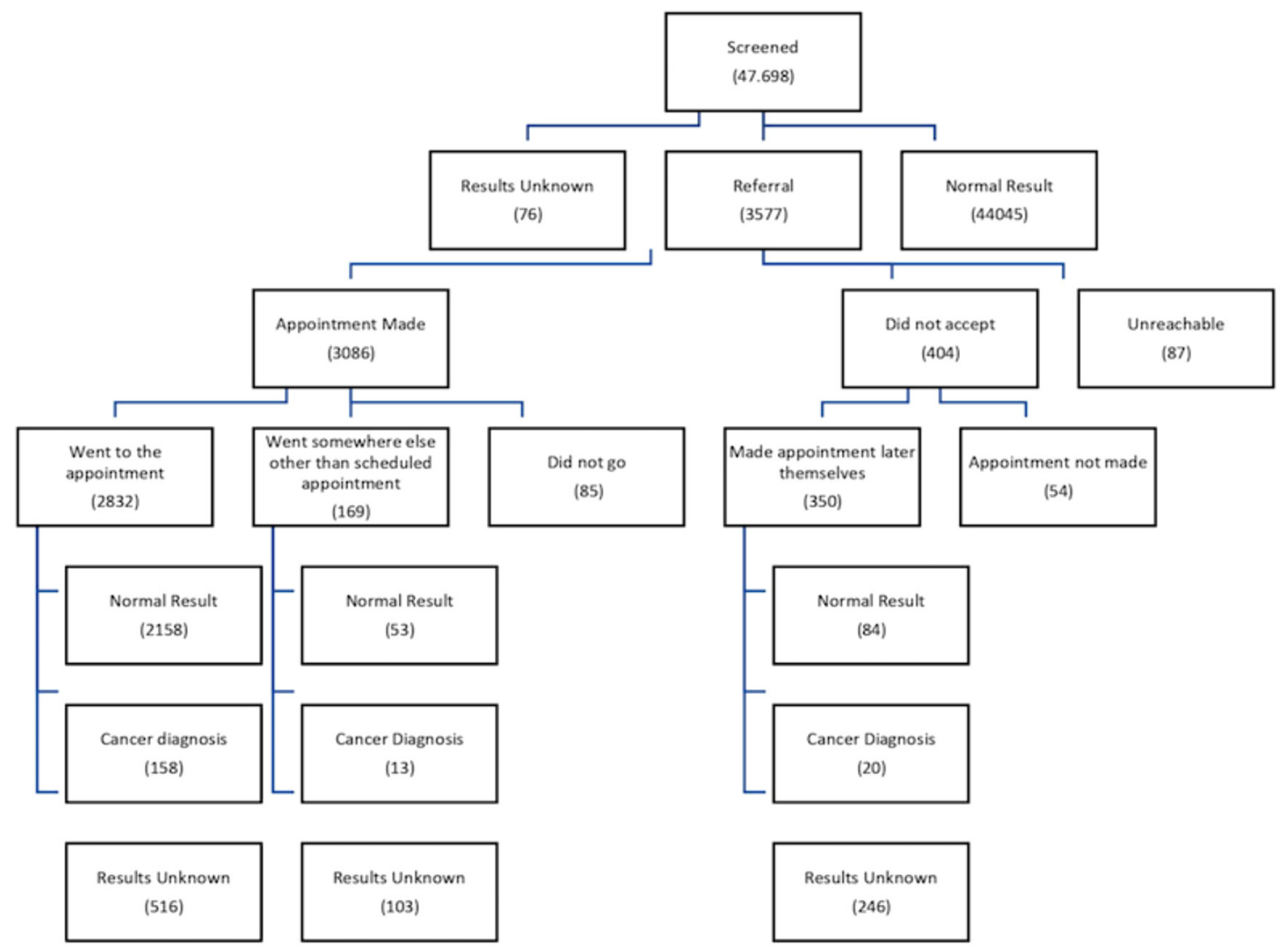

Figure 2. Summary of screening program enrollment and follow-up

Appointment made: These are the women who were contacted for further testing and scheduled their appointments. Went to the appointment: This group includes participants who went to the scheduled appointments. Went somewhere else: These participants had a scheduled appointment, but decided to go somewhere else, in a different time. Did not accept: These refer to the participants who declined the offer of scheduling an appointment. Made appointment later themselves: these women, who had previously declined to schedule an appointment, made their own appointments later on. 
50-59 and 40-49 (14). In addition, we found that onethird of all those diagnosed with some sort of cancer were under fifty (31\%). Considering the fact that the sensitivity of mammography is lower in the age groups below 50 (15), this ratio could also be higher in reality. This finding suggests screening programs may benefit from starting at an earlier age. Similarly, literature from developed countries suggests starting mammography screenings at an earlier age is associated with mortality rates of up to $23 \%$ (7). Starting the screening programs at age 40, long-term follow-up randomized protocols from the UK also provided supporting evidence of benefits (11).

Our study found that for women who received further testing and treatment in the center where they scheduled the appointment, the time between testing, diagnosis, and eventual treatment was earlier. This is also partly due to reaching out to individuals and making scheduling easier by phone. This practice is known to increase the uptake of follow-up services and also timeliness of interventions (16). This could result in less early detection and, as a result, a higher chance of survival.Mobile screening programs, such as this pilot, also increase access to diverse and rural populations that might otherwise be overlooked (12). In addition, the levels of follow-up were much higher when the patient went to the scheduled appointment rather than a place of their choosing instead.

\section{Study Limitations}

This screening program only used mammography as a screening tool. However, other radiological methods could have higher sensitivity and specificity for the detection of masses in younger women. In the younger age groups, the results may be skewed. However, the literature suggests mammography is still the best option considering logistics, costs, and the need for specialized personnel (13).

Participation in the screening program was open to everyone passing by the KETEM and there was no sampling used in this pilot study. It is hard to stipulate the breast cancer levels in the target population without actual sampling methods for participant selection being used. In addition, our sample was among the 2,529.072 women living in Istanbul at that time. While the screening was done on almost 3500 women, data on only 2400 was completed after the follow up time. While there is no information on people who did not respond, some were added to the database afterwards to alleviate this issue. Nonetheless, this could have skewed the results due to factors related to non-responsiveness.

The follow-up time was short in this study, focusing on the diagnosis as the end point. Mortality rates are not discussed, and further studies could benefit from looking at the 5 or 10 -year survival rate in this population.
However, this study also has several strengths. Primarily, this screening program was the largest of its kind in Turkey, a country with free access to screening and breast cancer treatment. In addition, a centralized electronic medical records keeping system allowed for high levels of follow-up during the data collection phase. As a pilot program, this study provides insights for nationwide scale-up programs.

\section{Conclusion}

This study focuses on the procedure of the screening program. However, successful implementation also requires more profound insight into referrals of screening invitations. Understanding the reasons behind the refusal or possible barriers is essential for population-wide impact.

We recommend the following considerations before implementing a nationwide screening program:

- The process needs to be planned as a continuity of care, not in silos such as "screening" or "treatment". A central database and authority on screening and follow-up could be beneficial in implementing the analysis of data (deaths averted, costs saved) and policy development.

- Standardization of screening, diagnosis, and data collection is a vital part of successful programs.

- Sensitization and an overall increase in "demand" for preventive care should be part of such programs to increase uptake.

- Novel follow-up methodologies could be costeffective alternatives to prevent loss in follow-up, such as automated calls or short message service reminders.

- To increase uptake of screening by the target population, further actions are needed that focus on understanding the reasons for rejecting being screened, or scheduling appointments. These follow-up procedures on people who reject them should be incorporated into the initial implementation.

\section{Ethics}

Ethics Committee Approval: The study was approved by the Istanbul Medeniyet University Goztepe Training and Research Hospital Clinical Research Ethics Committee (date: 27.01.2021, approval number: 2021/0055).

Informed Consent: No informed consent was sought as the study only used data from the existing databases.

\section{Authorship Contributions}

Concept: A.E.G., A.S., Design: A.S., G.S., Data Collection or Processing: A.E.G., K.K., Analysis or Interpretation: I.M., E.E.S., Literature Research: G.T., K.K., Writing: A.S., I.M.

Conflict of Interest: No conflict of interest was declared by the authors.

Financial Disclosure: The authors declared that this study received no financial support. 


\section{References}

1. IARC, age-standardized (World) Incidence Rates, Breast, All ages, International Agency for Research on Cancer, WHO 2018. Available from:http://gco.iarc.fr/today

2. T.C. Sağlık Bakanlığı, Türkiye kanser İstatistikleri 2016, Türkiye Cumhuriyeti Sağlık Bakanlığı Halk Sağlığı Genel Müdürlüğü. 2019. Available from: https://hsgm.saglik.gov.tr/depo/birimler/ kanser-db/istatistik/Trkiye_Kanser_statistikleri_2016.pdf

3. Howlader N, Noone AM, Krapcho $M$ et al. SEER Cancer Statistics Review, 1975-2017, National Cancer Institute. Bethesda, MD, https://seer.cancer.gov/csr/1975_2017/, based on November 2019 SEER data submission, posted to the SEER web site, April 2020.

4. American Cancer Society. Breast cancer facts \& figures $2017-$ 2018. Available from: https://www.cancer.org/content/dam/ cancer-org/research/cancer-facts-and-statistics/breast-cancerfacts-and-figures/breast-cancer-facts-and figures-2017-2018. pdf.

5. Selda S. Meme Kanseri Taraması : Son Yenilikler Neler ? TSK Koruyucu Hekim Bülteni 2011;10:193-200.

6. Bjurstam NG, Björneld LM, Duffy SW. Updated results of the Gothenburg Trial of Mammographic Screening. Cancer 2016;122:1832-5.

7. Armstrong K, Moye E, Williams S, Berlin JA, Reynolds EE. Screening mammography in women 40 to 49 years of age: A systematic review for the American College of Physicians. Ann Intern Med 2007;146:516-26.

8. Moss SM, Wale C, Smith R, Evans A, Cuckle H, Duffy SW. Effect of mammographic screening from Age 40 years on breast cancer mortality in the UK Age trial at 17 years follow-up: a randomized controlled trial. Lancet Oncol 2015;16:1123-32.

9. American Cancer Society, Breast Cancer Early Detection and Diagnosis, Recommendations for the Early Detection of Breast Cancer, 2016. Available from: https://www.cancer. org/content/dam/CRC/PDF/Public/8579.00.pdf

10. Türkiye Istatistik Kurumu, Adrese Dayalı Nüfus Kayıt Sistemi Sonuçları, 2019 https://data.tuik.gov.tr/Bulten/Index?p=AdreseDayali-Nufus-Kayit-Sistemi-Sonuclari-2019-33705

11. Duffy SW, Vulkan $D$, Cuckle $H$, et al. Effect of mammographic screening from age 40 years on breast cancer mortality (UK Age trial): final results of a randomised, controlled trial. Lancet Oncol 2020;21:1165-72.

12. Stanley E, Lewis MC, Irshad A, et al. Effectiveness of a mobile mammography program. AJR Am J Roentgenol 2017;209:1426-9.

13. Siu AL; U.S. Preventive Services Task Force. Screening for breast cancer: U.S. Preventive services task force recommendation statement. Ann Intern Med 2016;164:279-96.

14. ECIBC, European guidelines on breast cancer screening and diagnosis, The European Commission's science and knowledge service. 2020 Available from:https://healthcarequality.jrc.ec.europa.eu/european-breast-cancer-guidelines

15. Kerlikowske K, Grady D, Barclay J, Sickles EA, Ernster V. Effect of age, breast density, and family history on the sensitivity of first screening mammography. JAMA 1996;276:33-8.

16. Schapira MM, Barlow WE, Conant EF, et al. Communication practices of mammography facilities and timely follow-up of a screening mammogram with a BI-RADS 0 assessment. Acad Radiol 2018;25:1118-27. 